\title{
ВОЗМОЖНОСТИ ПРИМЕНЕНИЯ ЭКОЛОГИЧЕСКОГО БЛОКА КРИТЕРИАЛЬНЫХ ОГРАНИЧЕНИЙ В ЭКОНОМИКО-МАТЕМАТИЧЕСКОМ МОДЕЛИРОВАНИИ ОРГАНИЧЕСКОГО ПРОИЗВОДСТВА АПК ${ }^{1}$
}

\author{
О.Ю. Воронкова \\ Алтайский государственный университет (Барнаул, Россия)
}

\begin{abstract}
Представлена методика параллельной оптимизации структуры посевных площадей для расчета экономико-математических моделей при традиционной и ориентированной на производство органической продукции системе землепользования, отличающаяся введением дополнительного блока экологических критериальных ограничений: резерв земель, пригодных для производства органической продукции, валовой объем производства органической продукции и затраты на ее производство. На основе предложенной методики рассчитана экономико-математическая модель и доказана эффективность функционирования зонального агроэкокластера «Предгорья Алтая». С учетом полного вовлечения в производственный сельскохозяйственный производственный оборот земель, пригодных для производства органической продукции, уровень рентабельности составил 39,7\% против 17,3\% при оптимизации структуры посевных площадей в традиционной системе сельскохозяйственного производства.

Ключевые слова: экономико-математическое моделирование, органическая продукция, органически ориентированное производство, органически применимая залежь, оптимизация землепользования, эффективность производства.
\end{abstract}

\section{FEATURES OF THE UNIT APPLICATION OF ENVIRONMENTAL CRITERIA OF THE RESTRICTIONS IN ECONOMIC- MATHEMATICAL MODELING THE DEVELOPMENT OF ORGANIC AGRICULTURAL PRODUCTION}

\begin{abstract}
O. Yu. Voronkova
Altai State University (Barnaul, Russia)

The article presents a method of parallel optimization of structure of sowing areas for the calculation of economic-mathematical models in traditional and oriented towards organic production the land use system, characterized by the introduction of an additional unit of environmental criteria restrictions: provision of land suitable for organic production, gross production volume of organic products and the cost of its production. Based on the proposed methodology the mathematical model and proved the effectiveness of the functioning of the zonal agroecosystem "Foothills of Altai". Subject to full involvement in production of agricultural production, the turnover of land suitable for organic production, the level of profitability was of $39.7 \%$, against $17.3 \%$ at optimization of the structure of sown areas under traditional agricultural production.

Keywords: economic and mathematical modeling, organic produce, organically oriented production, organically applicable Deposit, optimization of land use, production efficiency.
\end{abstract}

Исследование выполнено при финансовой поддержке РФФИ, проект № 16-02-00235 «Экономическая оценка природно-ресурсного потенциала юга Западной Сибири и зонирование территории для производства экологически чистой сельскохозяйственной продукции». 
$\mathrm{B}$ ведение. Основным критерием эффективного землепользования является выход продукции и получение прибыли с единицы площади. В то же время с потребительской точки зрения наибольший интерес представляет энергетическая ценность произведенной на данной площади сельскохозяйственной продукции и ее экологическая безопасность. Вследствие этого становится актуальной задача эколого-экономической оценки сельскохозяйственного производства, для комплексного решения которой нами предлагается использовать экономико-математическую модель оптимизации структуры посевных площадей с введением дополнительного блока органических (экологических) критериальных ограничений.

Методы исследования. Теоретическую и методологическую основу исследования составили труды отечественных и зарубежных ученых по проблемам сельскохозяйственного производства органической продукции; вопросам развития земельных отношений; экономико-математическому моделированию. Методологической основой послужил системный подход, позволивший обеспечить комплексность и целенаправленность исследования. В работе также были использованы аналитический, расчетно-конструктивный, экономико-статистический, экономико-математический, монографический методы исследования.

Результаты исследования. В процессе исследования была предпринята попытка сформировать при помощи ЭММ оптимизированную модель землепользования зонального агроэкокластера «Предгорья Алтая» на основе параллельного функционирования как традиционно сложившейся индустриальной системы ведения сельскохозяйственного производства, так и органически ориентированной системы. Считаем обоснованным, что переход к органически ориентированной системе сельскохозяйственного производства должен быть поэтапным, с постепенным введением в сельскохозяйственный оборот залежных и неиспользуемых земель.

Постановка задачи. В проектируемом агроэкокластере «Предгорья Алтая» должна быть сформирована такая структура посевных площадей, которая обеспечивала бы получение максимума сельскохозяйственной продукции с каждого гектара земли при условии одновременного параллельного ведения индустриального и органически ориентированного землепользования, с учетом почвенного плодородия, условий местности, требований агротехники, соблюдения севооборотов, экономической эффективности производства отдельных видов культур, договорных обязательств и планов продажи экологически безопасного продовольствия.
По условиям построения модели требуется, исходя из имеющихся производственных ресурсов, определить наиболее оптимальную структуру посевных площадей как по индустриальной, так и по органической системе землепользования, которая обеспечила бы выполнение планов по продажам продовольствия, покрывала внутренние потребности хозяйствующего субъекта при максимальном экономическом эффекте. В качестве критерия оптимальности в задаче может выступать: максимум валовой или товарной продукции в денежном выражении, максимум производства определенного вида продукции в натуральном выражении, максимум чистой прибыли.

Предположительная цена реализации органической сельскохозяйственной продукции выше аналогичной, произведенной по традиционной агротехнологии, минимум на $20-40 \%$. Также необходимо дополнительно заложить 10-15\% затрат на изменение агротехнологии возделывания культур, сертификацию, рекламу, продвижение продукции.

Экономико-математическая модель оптимизации структуры посевных площадей представлена в трудах отечественных ученых [2-6], в математической формулировке имеет следующий вид.

Определить максимум функции (максимум чистого дохода)

$$
Z_{\max }=\sum_{j \in A} c_{j} x_{j}-k,
$$

где $C_{j}$ - объем валовой продукции в денежном выражении, получаемой с 1 га посевов $j$-ой культуры;

$x_{j}$ - посевная площадь $j$-ой культуры;

$k$ - производственные затраты на возделывание множества культур А.

1) Ограниченность земельных ресурсов:

$$
\sum_{j \in A} a_{i j} x_{j} \leq b_{i}(i \in M),
$$

где $a_{i j}$ - затраты земельного ресурса $i$-го вида;

$b_{i}$ - объем земельного ресурса $i$-го вида;

$M$ - множество видов земельного ресурса.

2) Определение производственных затрат:

$$
\sum_{j \in D} d_{i j} x_{j}=K,
$$

где $D$ - множество видов производственных затрат;

$d_{i j}$ - производственные затраты в расчете на 1 га возделываемой j-ой культуры.

3) Выполнение агротехнических требований возделывания сельскохозяйственных культур и некоторых организационно-экономических условий:

$$
\sum_{j \in A} x_{j}><Q_{j},
$$


где $Q$ - пределы насыщения севооборотов отдельными культурами или группами культур;

или

$$
\sum_{j \in A} a_{i j} x_{j} \leq a_{i j}^{\Theta} x_{j}
$$

где $a_{i j}, a_{i j}^{\ominus}-$ коэффициенты соотношения между предшественниками и отдельными культурами.

Обеспечение потребности животноводства кормами собственного производства:

$$
\sum_{j \in A} v_{i j} x_{j} \geq V_{i}
$$

где $V_{i j}$ - выход корма і-го вида с 1 га посева сельскохозяйственных культур;

$V_{i}$ - потребность в кормах і-го вида.

Представляется целесообразным составление трех вариантов экономико-математических моделей для агроэкокластера «Предгорья Алтая». Первый вариант предусматривает оптимизацию существующей структуры пахотных угодий сельскохозяйственных товаропроизводителей предгорной зоны при полном сохранении традиционной системы ведения земледелия. Второй вариант предполагает введение в структуру посевных площадей залежей и неиспользуемой площади пашни, или органически применимой залежи (ОПЗ), в количестве 50000 га, а третий вариант - вовлечение в сельскохозяйственный оборот всех неиспользуемых пахотных земель и залежей Предгорной зоны Алтайского края (ОПЗ) в количестве 181333 га. Во втором и третьем варианте предусмотрено получение органической продукции с площади органически применимой залежи, а также внесение органических удобрений на площади ОПЗ.

Общая площадь предгорной зоны составляет 1899 тыс. га земли, в том числе 1722 тыс. га сельскохозяйственные угодья, 728 тыс. га - пашня, 266 тыс. га - естественные сенокосы, 680 тыс. га пастбища. В соответствии с агротехническими требованиями севооборотов определены следующие минимально и максимально возможные границы возделывания отдельных культур или групп сельскохозяйственных культур в процентах от общей площади пашни.

Таблица 1

Агротехнические требования севооборотов предгорной зоны Алтайского края

\begin{tabular}{|l|c|c|}
\hline $\begin{array}{c}\text { Культуры или группы } \\
\text { культур }\end{array}$ & $\begin{array}{c}\text { Нижняя гра- } \\
\text { ница, \% }\end{array}$ & $\begin{array}{c}\text { Верхняя гра- } \\
\text { ница, \% }\end{array}$ \\
\hline $\begin{array}{l}\text { Зерновые и зернобобо- } \\
\text { вые культуры }\end{array}$ & 50 & 60 \\
\hline Технические культуры & 5 & 8 \\
\hline Овощи, картофель & 1 & 2 \\
\hline Кормовые культуры & 15 & 30 \\
\hline Пар & 10 & 13 \\
\hline
\end{tabular}

В результате решения экономико-математической задачи в программе EXCEL по первому варианту была оптимизирована существующая структура посевных площадей. Оптимизированная площадь сельскохозяйственных угодий составила 1722,5 тыс. га, пашни - 728 тыс. га, сенокосов - 265,9 тыс. га, пастбищ - 680 тыс. га, залежей - 46,3 тыс. га, многолетних насаждений $-2,2$ тыс. га.

Таблица 2

Оптимизированная структура посевных площадей в хозяйствах предгорной зоны по первому варианту (традиционная система земледелия)

\begin{tabular}{|l|c|c|c|c|c|}
\hline $\begin{array}{l}\text { Показа- } \\
\text { тели }\end{array}$ & $\begin{array}{c}\text { Суще- } \\
\text { ствую- } \\
\text { щая пло- } \\
\text { щадь, га }\end{array}$ & $\begin{array}{c}\text { к ито- } \\
\text { гу }\end{array}$ & $\begin{array}{c}\text { По опти- } \\
\text { мально- } \\
\text { му реше-- } \\
\text { нию }\end{array}$ & $\begin{array}{c}\% \\
\text { к ито- } \\
\text { гу }\end{array}$ & $\begin{array}{c}\text { Откло- } \\
\text { нения } \\
\text { (+;-), } \\
\text { га }\end{array}$ \\
\hline $\begin{array}{l}\text { Зерно- } \\
\text { вые, все- } \\
\text { го }\end{array}$ & 393424 & 54,0 & 393990 & 54,1 & 566 \\
\hline $\begin{array}{l}\text { Техниче- } \\
\text { ские куль- } \\
\text { туры }\end{array}$ & 45640 & 6,3 & 45671 & 6,3 & 31 \\
\hline $\begin{array}{l}\text { Карто- } \\
\text { фель }\end{array}$ & 7212 & 1,0 & 7214 & 1,0 & 2 \\
\hline Овощи & 1261 & 0,2 & 1261 & 0,2 & 0 \\
\hline $\begin{array}{l}\text { Кормо- } \\
\text { вые куль- } \\
\text { туры }\end{array}$ & 121468 & 16,7 & 111752 & 15,4 & -9716 \\
\hline Пар & 23974 & 3,3 & 33093 & 4,5 & 9119 \\
\hline $\begin{array}{l}\text { Неис- } \\
\text { пользуе- } \\
\text { мые зем- } \\
\text { ли }\end{array}$ & 135000 & 18,5 & 135000 & 18,5 & 0 \\
\hline Пашня & 727979 & 100 & 727979 & 100 & 0 \\
\hline
\end{tabular}

По оптимальному решению площадь пашни используется полностью и составляет 728 тыс. га. Наибольший удельный вес в оптимальной структуре пашни занимают зерновые культуры и составляют 54,1\% (394 тыс. га), что выше фактической на 566 га. По оптимальному решению увеличилась площадь яровой пшеницы на 2172 га, ячменя — на 141 га, гречихи — на 710 га. Площадь подсолнечника увеличилась на 96 га, в целом площадь под техническими культурами увеличилась на 31 га. Площадь кормовых культур сократилась на 9,7 тыс. га, в то же время площадь пара по оптимальному решению составила 4,5\% (33,1 тыс. га), увеличившись на 9,1 тыс. га. Оптимизированная структура посевных площадей в большей степени, чем существующая, соответствует требованиям севооборотов для данной зоны.

Рассмотрим второй вариант экономико-математической модели оптимизации структуры посевных площадей с учетом введения в сельскохозяйственный оборот 50 тыс. га органически при- 
менимой залежи для целей производства экологического продовольствия на данной площади. С этой целью в экономико-математическую модель введем дополнительно критериальный блок экологических переменных и ограничений, в том числе внесение органических удобрений, дополнительные материальные и трудовые затраты на ведение органической системы земледелия, а также отличные от традиционной системы земледелия урожайность, себестоимость и цену реализации экологического продовольствия.

Таблица 3

Оптимизированная структура посевных

площадей в хозяйствах предгорной зоны по второму варианту (параллельное ведение земледелия по традиционной и органически ориентированной системам)

\begin{tabular}{|l|c|c|c|c|c|}
\hline $\begin{array}{c}\text { Показа- } \\
\text { тели }\end{array}$ & $\begin{array}{c}\text { Пло- } \\
\text { щадь, } \\
\text { га }\end{array}$ & $\begin{array}{c}\% \\
\text { к ито- } \\
\text { гу }\end{array}$ & $\begin{array}{c}\text { По опти- } \\
\text { мально- } \\
\text { му реше- } \\
\text { нию }\end{array}$ & $\begin{array}{c}\text { к ито- } \\
\text { гу }\end{array}$ & $\begin{array}{c}\text { Откло- } \\
\text { нения } \\
\text { (+;-), } \\
\text { га }\end{array}$ \\
\hline $\begin{array}{l}\text { Зерновые, } \\
\text { всего }\end{array}$ & 393424 & 54,0 & 402121 & 51,7 & 8697 \\
\hline $\begin{array}{l}\text { Техниче- } \\
\text { ские куль- } \\
\text { туры }\end{array}$ & 45640 & 6,3 & 47925 & 6,2 & 2285 \\
\hline $\begin{array}{l}\text { Карто- } \\
\text { фель }\end{array}$ & 7212 & 1,0 & 7764 & 1,0 & 552 \\
\hline Овощи & 1261 & 0,2 & 1463 & 0,2 & 202 \\
\hline $\begin{array}{l}\text { Кормовые } \\
\text { культуры }\end{array}$ & 121468 & 16,7 & 125135 & 16,1 & 3667 \\
\hline Пар & 23974 & 3,3 & 62238 & 8,0 & 38264 \\
\hline $\begin{array}{l}\text { Неисполь- } \\
\text { зуемые } \\
\text { земли }\end{array}$ & 135000 & 18,5 & 131333 & 16,9 & -3667 \\
\hline Пашня & 727979 & 100 & 777979 & 100 & 50000 \\
\hline
\end{tabular}

В данном варианте экономико-математической модели не осталось неиспользуемой пашни. Наибольший удельный вес в оптимальной структуре пашни занимают зерновые культуры, они составляют 51,7\% (402,1 тыс. га), что выше фактической на 8,7 тыс. га. Оптимальная структура посевных площадей по данному варианту практически полностью соответствует требованиям севооборотов для данной зоны.

Рассмотрим третий вариант экономико-математической модели оптимизации структуры посевных площадей сельхозтоваропроизводителей предгорной зоны с учетом введения всей площади залежных земель и неиспользуемых пахотных угодий (органически применимая залежь) для целей ведения органически ориентированного землепользования. Так же как и во второй оптимизационной модели параллельно введем дополнительный блок переменных и ограничений по производству экологической продукции.
Таблица 4

Оптимизация структуры посевных площадей в хозяйствах предгорной зоны по третьему варианту (параллельное ведение земледелия по традиционная и органически ориентированной системам)

\begin{tabular}{|l|c|c|c|c|c|}
\hline $\begin{array}{c}\text { Показа- } \\
\text { тели }\end{array}$ & $\begin{array}{c}\text { Пло- } \\
\text { щадь, } \\
\text { га }\end{array}$ & $\begin{array}{c}\% \\
\text { к ито- } \\
\text { гу }\end{array}$ & $\begin{array}{c}\text { По оп- } \\
\text { тималь- } \\
\text { ному } \\
\text { реше- } \\
\text { нию }\end{array}$ & $\begin{array}{c}\% \\
\text { к ито-- } \\
\text { гу }\end{array}$ & $\begin{array}{c}\text { Откло- } \\
\text { нения } \\
\text { (+;-), } \\
\text { га }\end{array}$ \\
\hline $\begin{array}{l}\text { Зерновые, } \\
\text { всего }\end{array}$ & 393424 & 54,0 & 464587 & 60,0 & 71163 \\
\hline $\begin{array}{l}\text { Техниче- } \\
\text { ские куль- } \\
\text { туры }\end{array}$ & 45640 & 6,3 & 61945 & 8,0 & 16305 \\
\hline $\begin{array}{l}\text { Карто- } \\
\text { фель }\end{array}$ & 7212 & 1,0 & 9834 & 1,3 & 2622 \\
\hline Овощи & 1261 & 0,2 & 1781 & 0,2 & 520 \\
\hline $\begin{array}{l}\text { Кормовые } \\
\text { культуры }\end{array}$ & 121468 & 16,7 & 158734 & 20,5 & 37266 \\
\hline Пар & 23974 & 3,3 & 77431 & 10,0 & 53457 \\
\hline $\begin{array}{l}\text { Неисполь- } \\
\text { зуемые } \\
\text { земли }\end{array}$ & 135000 & 18,5 & 0 & 0 & -135000 \\
\hline Пашня & 727979 & 100 & 774312 & 100 & 46333 \\
\hline
\end{tabular}

Оптимальная структура посевных площадей по третьему варианту полностью соответствует требованиям севооборотов для данной зоны. Для планомерного перехода части сельскохозяйственных предприятий на принципы органически ориентированного землепользования и производство качественного и экологически чистого отечественного продовольствия необходим успешный опыт функционирования экологически ориентированных компаний, а также инновационные разработки в сфере АПК, реализация которых на уровне региона может быть осуществлена через систему зональных агроэкокластеров.

Таблица 5

Распределение вводимой органически применимой залежи по группам культур

\begin{tabular}{|c|c|c|c|c|}
\hline \multirow[t]{2}{*}{ Показатели } & \multicolumn{2}{|c|}{$\begin{array}{l}\text { Введение } 50000 \\
\text { га ОПз (второй } \\
\text { вариант) }\end{array}$} & \multicolumn{2}{|c|}{$\begin{array}{c}\text { Введение } 181333 \\
\text { га ОПз } \\
\text { (третий вариант) }\end{array}$} \\
\hline & га & $\%$ & га & $\%$ \\
\hline Зерновые & 8697 & 17,4 & 71163 & 39,2 \\
\hline Технические & 2285 & 4,6 & 16305 & 9,0 \\
\hline $\begin{array}{l}\text { Картофель } \\
\text { и овощи }\end{array}$ & 754 & 1,5 & 3142 & 1,7 \\
\hline Кормовые & 0 & 0 & 37266 & 20,6 \\
\hline Пар & 38264 & 76,5 & 53457 & 29,5 \\
\hline Итого & 50000 & 100 & 181333 & 100 \\
\hline
\end{tabular}

Наибольший удельный вес в структуре вовлеченной в сельскохозяйственный производственный 
оборот органически применимой залежи по второму варианту будет составлять пар, так как он является хорошим предшественником для зерновых, технических культур, картофеля и овощей. В существующей в настоящее время структуре землепользования данной зоны площадь пара не соответствует требованиям севооборотов.

Финансовые результаты, полученные в результате оптимизации структуры посевных площадей

\begin{tabular}{|l|c|c|c|c|}
\hline \multicolumn{1}{|c|}{ Показатели } & $\begin{array}{c}\text { Факти- } \\
\text { ческие }\end{array}$ & $\begin{array}{c}\text { По 1 ва- } \\
\text { рианту }\end{array}$ & $\begin{array}{c}\text { По 2 ва- } \\
\text { рианту }\end{array}$ & $\begin{array}{l}\text { По 3 ва- } \\
\text { рианту }\end{array}$ \\
\hline $\begin{array}{l}\text { Выручка, тыс. } \\
\text { руб. }\end{array}$ & 1413,8 & 1549,7 & 1728,6 & 2914,5 \\
\hline $\begin{array}{l}\text { Себестоимость, } \\
\text { тыс. руб. }\end{array}$ & 1230,0 & 1314,7 & 1406,7 & 2086,4 \\
\hline $\begin{array}{l}\text { Прибыль, тыс. } \\
\text { руб. }\end{array}$ & 183,8 & 227,3 & 321,9 & 828,1 \\
\hline $\begin{array}{l}\text { Рентабель- } \\
\text { ность, тыс. руб. }\end{array}$ & 14,9 & 17,3 & 22,9 & 39,7 \\
\hline
\end{tabular}

Обсуждение. Расчет трех вариантов экономико-математических моделей показал экономическую эффективность постепенного перехода к органически ориентированному землепользованию. При расчете экономико-математических моделей оптимизации землепользования нами был разработан и применен метод параллельной оптимизации структуры посевных площадей при традиционной системе землепользования и системе земледелия с учетом экологизации. Расчет предложенных вариантов оптимизации структуры посевных площадей, в том числе с частичным и полным вовлечением в сельскохозяйственный оборот органически применимой залежи предполагает жизнеспособность предложенного проекта зонального агроэкокластера «Предгорья Алтая» [1].

Формирование органически ориентированной системы ведения сельского хозяйства не означает отказ от индустриального сельскохозяйственного производства. По нашему мнению, и органическая, и индустриальная системы ведения земледелия могут эффективно функционировать параллельно друг с другом, постепенно трансформируясь в такую аграрную технологию, которая сможет удовлетворить текущие и предполагаемые потребности населения в качественном и экологически безопасном продовольствии.

Заключение. Для планомерного перехода части сельскохозяйственных предприятий на принципы и производство качественного и экологически чистого отечественного продовольствия необходим успешный опыт функционирования экологически ориентированных компаний, а также инновационные разработки в сфере АПК, реализация которых на уровне региона может быть осуществлена через систему зональных агроэкокластеров. Реализация предложенных рекомендаций возможна при наличии действенного организационно-экономического механизма государственной поддержки и стимулирования деятельности экологически ориентированного сельскохозяйственного предпринимательства, которое, в свою очередь, следует рассматривать как важный составной элемент структуры мирового рынка органической продукции, на сегодняшний день находящегося в стадии динамичного развития.

\section{БИБЛИОГРАФИЧЕСКИЙ СПИСОК}

1. Барышников Г.Я., Воронкова О.Ю., Барышникова О.Н., Ельчищев Е.А. Районирование территории Алтайского края для производства экологически чистой сельскохозяйственной продукции. Барнаул, 2016. 136 c.

2. Глухов В.В., Медников М.Д., Коробко С. Б. Математические методы и модели для менеджмента. 2-е изд., испр. и доп. СПб., 2005.

3. Дик В. В. Методология формирования решений в экономических системах и инструментальные среды их поддержки. М., 2001.

4. Катаргин Н. В. Экономико-математическое моделирование в Excel. Саратов, 2013. 83 c. URL: http:// www.iprbookshop.ru/17777.html. ЭБС «IPRbooks».

5. Хачатрян Н. К. Математическое моделирование экономических систем. М., 2008. 158 с.

6. Шикин Е. В., Чхартишвили А. Г. Математические методы и модели в управлении. М., 2004. 440 с.

\section{REFERENCES}

1. Baryshnikov G. Ya., Voronkova O. Yu., Baryshnikova O. N., El'chishchev E. A. (2016) Rajonirovanie territorii Altajskogo kraya dlya proizvodstva ehkologicheski chistoj sel'skohozyajstvennoj produkcii. Barnaul. 136 p. (in Russian). 
2. Gluhov V.V., Mednikov M. D., Korobko S. B. (2005) Matematicheskie metody i modeli dlya menedzhmenta. 2nd ed. Saint Petertsburg. (in Russian).

3. Dik V.V. (2001) Metodologiya formirovaniya reshenij v ehkonomicheskih sistemah i instrumental'nye sredy ih podderzhki. Moscow. (in Russian).

4. Katargin N.V. (2013) Ekonomiko-matematicheskoe modelirovanie v Excel. Saratov. 83 p. URL: http:// www.iprbookshop.ru/17777.html. IPRbooks. (in Russian).

5. Hachatryan N. K. (2008) Matematicheskoe modelirovanie ehkonomicheskih system. Moscow. 158 p. (in Russian).

6. Shikin E.V. (2004) Matematicheskie metody i modeli v upravlenii. Moscow. 440 p. (in Russian). 